\title{
A Universidade viva na relação com as classes populares
}

\author{
The University alive in relation to the popular classes
}

\author{
Ivanise Monfredini ${ }^{1}$ \\ ${ }^{1}$ Universidade Católica de Santos | Programa de Pós-graduação em Educação | Centro de \\ Ciências da Educação e Comunicação \\ Santos | SP | Brasil. Contato: imonfredini@gmail.com \\ http://orcid.org/0000-0001-8492-9826
}

Resumo: Este é um ensaio sobre a universidade brasileira, as suas possibilidades e limites neste momento de aprofundamento das contra reformas. Trata-se a relação entre a Universidade e as classes populares como alternativa analisada a partir das tendências privatistas das políticas de ensino superior no Brasil, bem como de ciência e tecnologia, nesse momento de transição do breve período do neodesenvolvimentismo para o de aprofundamento das contra reformas iniciadas na década de 1990. $\mathrm{O}$ ensaio é inspirado em depoimentos de pesquisadores brasileiros que tem atuado na universidade, junto com agricultores familiares, pequenos proprietários e assentados, catadores de material reciclável, organizados em cooperativas e associações. As análises estruturam-se no diálogo com as ideias de Dagnino (2015) e Leher (2015) sobre a Universidade, além de pesquisa bibliográfica e documental (legislações) sobre os temas abordados. Realiza-se um balanço das políticas de ensino superior e de ciência e tecnologia, consideradas no aspecto da inclusão e da relação com as classes populares. Privilegia-se o primeiro decênio deste século, breve período do neodesenvolvimentismo brasileiro encerrado com o aprofundamento das contra reformas em curso. Para iniciar analisa-se o ensino superior brasileiro. Na sequência, são abordadas as tendências nas políticas de ciência e tecnologia. Seguem-se as análises sobre as possibilidades e limites da relação entre universidade e classes populares, como alternativa que se realiza contraditoriamente. Conclui-se que a relação Universidade e classes populares se constitui como alternativa à recriação da primeira. A Universidade, ao contribuir com esses movimentos, recria-se.

Palavras-chave: Relação universidade e sociedade. Políticas de ensino superior. Políticas de ciência e Tecnologia.

Abstract: This is an essay on the Brazilian University, its possibilities and limits at this time of deepening of counter reforms. The aim is the relationship between the University and the Popular Classes as an alternative, that is analyzed from the privatist tendencies of higher education policies in Brazil, as well as from science and technology, in this moment of transition from the brief period of neodevelopment to the deepening of the counter reforms begun in the 1990s. The essay is inspired by interviews whith Brazilian researchers who have worked at the university with family farmers, smallholders and rural settlement, collectors of recyclable material, organized in cooperatives and associations. The analyzes are structured in the dialogue with the ideas of Dagnino (2015) and Leher (2015) on the University, as well as bibliographical and documentary research (legislations) on the topics addressed. Is carried out a review of the policies of higher education and of science and technology, considered in the aspect of inclusion and the relation with the popular classes. The first decade of this century is favored, a brief period of Brazilian neodevelopment, ending with the deepening of counter-reforms under way. To begin, Brazilian higher education is analyzed, indicating the more general trends in the field of public policies. Following, are addressed the trends in science and technology policies. Is followed the analysis of the possibilities and limits of the relationship between university and popular classes as an alternative that is carried out in a contradictory way. It is concluded that the relation between University and Popular Classes constitutes an alternative to the re-creation of the first. The University, in contributing to these movements, recreates itself.

Key words: Relationship university and society. Higher education policies. Science and Technology Policies.

\section{DOI: http://dx.doi.org/10.1590/S1414-407720190001000015}

Este é um artigo publicado em acesso aberto (Open Access) sob a licença Creative Commons Attribution Non-Commercial, que permite uso, distribuição e reprodução em qualquer meio, sem restrições desde que sem fins comerciais e que o trabalho original seja corretamente citado. https://creativecommons.org/licenses/by-nc/4.0/ 


\section{Introdução}

Aqui a gente tem o parque nacional que pega uma parte do município de [...], é patrimônio, é reserva da biosfera, são várias áreas prioritárias para conservação defendidas pelo Ministério do Meio Ambiente. Então é uma área de uma riqueza, de uma beleza cênica, e de necessidade mesmo de conservação. Por isso, essas pessoas sempre correram muito atrás disso. Existe um movimento ambientalista muito forte aqui na cidade. (Pesquisadora brasileira).

Este é um ensaio sobre a universidade brasileira, as suas possibilidades e limites neste momento de aprofundamento das contra reformas. Trata-se de pensar a relação entre a Universidade e as classes populares no Brasil, que suscita questões sobre a significação social dessa instituição.

Considera-se esta relação como uma alternativa, se analisada na relação com as tendências privatistas das políticas de ensino superior no Brasil, bem como de ciência e tecnologia, nesse momento de transição do período de implementação das contra reformas, na década de 1990, para o seu aprofundamento, em curso nesse momento histórico.

$\mathrm{O}$ ensaio é inspirado em depoimentos de pesquisadores brasileiros ${ }^{1}$ que refletem a tensão que permeia a universidade, especialmente quando as práticas orientam-se às classes populares.

Essas tensões ganham tonalidades mais fortes se pensadas no momento histórico atual de desmonte de políticas sociais, entre elas de educação, assim como de ciência e tecnologia, que impactam as universidades, que já estão, no caso brasileiro, há décadas, inseridas nos processos de privatização.

Junto com Minto (2006, p. 113) entendemos privatização como “[...] parte de um processo histórico, longo e complexo. Processo este que escapa às simples determinações políticas emanadas de dentro do próprio campo educacional" e que para serem entendidos devem ser considerados no plano internacional relacionados às "mudanças que se processaram nos padrões de acumulação do capitalismo mundial.

O momento atual é de aprofundamento das contra reformas iniciadas na década de 1990, que no plano internacional, atacam diretamente as conquistas civilizatórias obtidas no breve período que se estende do pós segunda guerra mundial, até a década de 1960.

No Brasil, a principal conquista desse período foi a legislação de proteção ao trabalho, a Consolidação das Leis do Trabalho (CLT). A ampliação de direitos sociais assim como das políticas públicas que lhes deram suporte, são conquistas mais recentes, obtidas pela pressão 
da sociedade civil organizada, especialmente após a aprovação da "Constituição Cidadã" de 1988. É este conjunto de conquistas que vem sendo desmontado de forma gradual desde então, e de forma rápida e autoritária, após o golpe que destituiu o governo de Dilma Roussef.

As contra reformas referem-se, como explica Behering (2008; 2012), aos processos regressivos que vem sendo implementados desde a década de 1990, a partir do abandono de um projeto comprometido com a inclusão econômica e política da maioria da população e com as possibilidades de ruptura com a heteronomia.

Consideradas as particularidades históricas de cada Estado, observam-se ataques semelhantes na Europa e na América Latina. Este cenário nos remete à análise de Mészáros (2002; 2007) quanto a irreformabilidade, incontrolabilidade e destrutividade do capital. A expansão do capital a cada crise de acumulação, ou seja, a reestruturação da economia, como a denomina Mészáros (2002), funda-se, especialmente após a segunda guerra mundial, em fatores irreconciliáveis: o desemprego estrutural e a superprodução; os gastos crescentes com o complexo militar-industrial e o acirramento do conflito capital e trabalho; e, finalmente, a industrialização do "terceiro mundo" que traz complicações competitivas ${ }^{2}$.

As tentativas de reorganizar a economia dentro dos moldes do capital financeiro (CHESNAIS, 1996), esbarram com seus próprios limites muito rapidamente. A mais recente tentativa de reorganização da economia pelas determinações da esfera financeira resultou na crise de 2008, mote para mais um conjunto de ataques aos direitos sociais que vão dissipando a ilusão conciliatória acalentada pelas conquistas do pós segunda guerra mundial.

No Brasil, o breve tempo decorrido entre a aprovação da Constituição Cidadã até o presente foi suficiente para disseminar a ilusão neodesenvolvimentista (FIRMIANO, 2016).

As tentativas de reorganizar a economia incluem mudanças nas políticas públicas que liberam o fundo público para o capital e desmontam a proteção ao trabalho, ao mesmo tempo que revestem de legalidade tais ações. Verifica-se então que determinados direitos de cidadania, como saúde e educação passam a ser oferecidos como serviços, tanto por instituições públicas como diretamente por empresas privadas.

Nesse sentido, a reforma da educação superior realizada na década de 1990, regulamentou a possibilidade de as instituições de ensino superior assumirem o caráter lucrativo, a partir do que se tornou permitido e esperado que explicitem seu rendimento com a oferta dos "serviços de ensino" e liberando esse serviço para comércio internacional, de acordo com a orientação da Organização Mundial do Comércio. 
A dívida pública também assume uma dimensão significativa na reorganização econômica, especialmente desde o final do século XX, como mecanismo de "transferência volumosa de recursos oriundos do trabalho para as mãos da burguesia financeira - nacional e internacional", como se refere Brettas (2012, p. 118).

Esses são alguns dos aspectos que permeiam os depoimentos dos pesquisadores entrevistados. As medidas de reorganização da economia em curso, são operadas no sentido de "afirmar o lugar do Brasil na estrutura global do capital como fornecedor de commodities e plataforma de valorização financeira", como afirma Firmiano (2016, p. 601), afetando diretamente os orçamentos das Universidades, especialmente as públicas.

Diante das consequências do ajuste econômico as universidades se veem obrigadas a recolocar os conceitos e ideias históricas que dão sentido e significado às suas atividades, especialmente no que se refere ao seu caráter de bem público.

Para este ensaio o aspecto tomado dos depoimentos foi o fazer pesquisa e extensão na relação direta com grupos e classes populares. Eles permitem uma reflexão de como podem se configurar alternativas nas Universidades, em meio à histórica opção política privatizante. Indicam uma possibilidade de produção de conhecimentos socialmente relevantes, que sobrevive nas Universidades. Para isso, realiza-se um balanço das políticas de ensino superior e de ciência e tecnologia, consideradas no aspecto da inclusão e da relação com as classes populares. Privilegia-se o primeiro decênio deste século, entre 2003 e 2013, breve período do neodesenvolvimentismo brasileiro encerrado com o aprofundamento das contra reformas em curso.

A opção por estruturar as reflexões a partir dos depoimentos deve-se à intenção de dar voz aos pesquisadores brasileiros que, nesse caso, desenvolvem seu trabalho junto à cooperativas e associações, principalmente de agricultores familiares ${ }^{3}$.

Nesse momento crítico da história do país, e da crise estrutural do capital, em que os recursos naturais, ecológicos e energéticos são disputados de forma acirrada e violenta, em que as políticas públicas de apoio aos agricultores familiares e povos originários são desmontadas, a atuação da Universidade junto a essas populações assume um caráter científico, político e social, relevante.

A bancada ruralista compõe a maioria do Congresso Nacional Brasileiro conforme levantamento realizado por Medeiros e Fonseca (2016), contando com 207 parlamentares. É

3 Nove dos doze entrevistados atuam junto à cooperativas ou associações de pequenos agricultores, ou assentamentos. Os outros três junto à cooperativas de catadores de materiais recicláveis. 
esta bancada junto com a empresarial, que vem realizando as mudanças jurídicas que liberam ao capital internacional, terras, recursos minerais e biológicos, além de desonerar ainda mais o preço do trabalho. Nesse sentido, no último dia 14 de julho foi aprovada a reforma trabalhista, a Lei 13.467 (BRASIL, 2017) (rever este trecho para colocar no parêntese somente a citação de autoria) (Referenciada), que suscita muitas dúvidas quanto a sua constitucionalidade, tendo em vista ferir, inclusive, diretrizes da Organização Internacional do Trabalho ratificadas pelo Brasil, como se manifesta a Associação Nacional dos Magistrados da Justiça do Trabalho (ANAMATRA, 2017).

As relações no campo também tem sido objeto de mudanças na legislação, dentre as quais vale destacar: a extinção do Ministério do Desenvolvimento Agrário (MDA), de acordo com a lei 13.341 de 29/09/2016 (BRASIL, 2016); a transferência das secretarias ligadas à reforma agrária e do Instituto de Colonização e Reforma Agrária (Incra) para a Casa Civil; a não liberação de novos recursos para os Programas Nacional de Alimentação Escolar (PNAE) e de Aquisição de Alimentos (PAA), que são fundamentais para os agricultores familiares; o contingenciamento progressivo do orçamento voltado para o Programa Nacional de Educação na Reforma Agrária (Pronera); a redução das áreas de proteção na Amazônia (MP 758 Transformada na Lei Ordinária 13.452/2017); a Lei no. 13.465 de 11/07/2017 que eliminou o conceito de uso social da terra. Paralelo a isso o Tribunal de Contas da União (TCU) dificulta o cadastro de famílias assentadas, como indica Firmiano (2016).

As mudanças em curso permitem identificar, mais uma vez, a particularidade histórica do Estado brasileiro, relacionada "[...] basicamente as formas irresolutas da questão da terra e do estatuto da força de trabalho [...]" (OLIVEIRA, 2005).

O Estado brasileiro é herdeiro dessas formas irresolutas, cujos eixos centrais para Martins (2011) são a reforma agrária, os deserdados da posse da terra e os latifundiários, transmutados em agronegócio.

Esse conjunto de ataques fragilizam ainda mais a vida dos trabalhadores rurais e urbanos, povos originários, além da Universidade. A violência do processo revela a destrutividade do capital, conforme indica Mészáros (2007; 2002), tendência que coloca em risco a própria vida no planeta.

$\mathrm{Na}$ América Latina a agroecologia, a agricultura familiar, os pequenos produtores, os trabalhadores rurais e urbanos, os povos originários, ocupam a linha de frente das vítimas dramaticamente afetadas nas suas condições de vida. Tendo em vista a importância das commodities na disputa capitalista internacional, como indica Leher (2015). 
Este é o principal motivo para a manutenção, nesse ensaio, dos depoimentos. Dizem respeito ao trabalho conjunto de pesquisadores e agricultores familiares, pequenos proprietários e assentados organizados em cooperativas e associações. Esse trabalho envolve direta ou indiretamente, a luta pela posse e manutenção da terra e dessa população na terra, a defesa e prática da agroecologia, aspectos que, no país e no mundo, nesse momento, demarcam um espaço tenso da luta entre capital e trabalho. Outro motivo é que, da perspectiva da Universidade, os depoimentos referem-se a práticas concretas, mantidas, em alguns casos, há décadas, na contracorrente do produtivismo e da privatização que caracterizam a universidade brasileira.

Dessa forma, os depoimentos inspiram uma reflexão sobre a significação social da Universidade brasileira. Expressam, contraditoriamente, as possibilidades ainda existentes nessa instituição.

Os depoimentos são todos de pesquisadores brasileiros que atuam em universidades públicas, federais e estaduais, de diferentes regiões ${ }^{4}$. Para este ensaio selecionaram-se os trechos sobre a percepção desses pesquisadores quanto ao trabalho desenvolvido junto às associações e cooperativas.

Os depoimentos inspiradores do ensaio serão citados como epígrafes a partir das quais os temas são tratados. A ideia não foi fazer a análise de discurso. A epígrafe foi o melhor lugar encontrado pela autora para citação do que inspirou o ensaio, porque coloca em destaque as vozes desses pesquisadores. A intenção foi a de ampliar as vozes desses pesquisadores, sujeitos de seu tempo e espaço, que, assim como outros colegas nas universidades brasileiras, percorrem caminhos semelhantes.

Em síntese, nesse ensaio, sob a inspiração dos depoimentos, analisa-se alternativas para a Universidade brasileira nesse momento crítico da história do país no diálogo com as análises de Dagnino (2015) e Leher (2015) sobre a Universidade.

Dagnino (2015) sugere a ideia de que a Universidade inverta a tradicional hierarquia da produção de conhecimento, considerando que outro projeto societário exige outra base tecnocientífica. Por meio do neologismo "ex vestigação" sugere pensar a produção de conhecimentos de fora para dentro. Não como “in” vestigação, mas como "ex" vestigação.

Para Leher (2015) os vínculos com os movimentos sociais são essenciais, tendo em vista a constante necessidade de análises mais aprofundadas que desvelem os desdobramentos

\footnotetext{
4 As identidades de todos os colaboradores são mantidas em sigilo. Aos entrevistados foi encaminhado o Termo de Concordância Livre e Consentido, e posteriormente as entrevistas transcritas, para a revisão deles.
} 
da crise estrutural do capital com o que a Universidade pode contribuir, e, de outro lado, a contribuição dos movimentos sociais para a construção de uma outra Universidade. Ao longo do texto retorna-se às contribuições desses autores.

O ensaio estrutura-se a partir de pesquisa bibliográfica e documental (legislações) sobre os temas abordados.

Para iniciar, trata-se do ensino superior brasileiro, de modo a indicar as tendências mais gerais em curso, tendo em vista a histórica privatização do ensino superior e os impactos das medidas para reorganizar a economia, após a crise de 2008, ou seja, o aprofundamento das contra reformas.

Na sequência, são abordadas as tendências nas políticas de ciência e tecnologia, também no marco do aprofundamento das contra reformas.

Em seguida, as análises sobre as possibilidades e limites da relação entre universidade e classes populares, como alternativa que se realiza contraditoriamente. Consideram-se duas vertentes principais dessa relação - com as cooperativas e com os movimentos sociais.

Conclui-se que a relação Universidade e classes populares se constitui como alternativa à recriação da primeira. A Universidade, ao contribuir com esses movimentos, recria-se.

\title{
O aprofundamento das contra reformas e as consequências para a Universidade
}

\begin{abstract}
Em 2016, houve um corte do orçamento inicial, e a partir desse corte foi respeitado o corte Então, fez uma previsão inicial baseado no projeto de lei orçamentária, depois disso houve um corte de $10 \%$ a $20 \%$ eu não lembro ao certo e aí foi cumprido esse orçamento. Agora, para 2017, o orçamento ele é igual ao orçamento de 2016, porém até agora está se pagando com 18 avos por mês e não 12 avos.[...] Havia o REUNI que passava pelas universidades, aumento de vagas, contratação, construção de prédios. Hoje você não tem mais nada disso, você tem dinheiro para manter a universidade. E muita das coisas que foram pactuadas no governo Dilma, não se mantém. (Pesquisador Brasileiro)
\end{abstract}

O Brasil é um país marcado por desigualdades sociais (MEDEIROS, SOUZA e CASTRO, 2015), no qual tem sido poucos os momentos históricos em que se identifica a existência de um pleno compromisso dos governos com a educação pública. Ao longo do tempo as políticas públicas para a educação estão marcadas por descontinuidades, omissões, e frequentes mudanças ministeriais.

A “educação do povo" interessou especialmente aos governos autoritários, especialmente Getúlio Vargas e militares, nos períodos de 1945 a 1964. O setor privado da educação superior, nesses diferentes períodos, sempre tiveram presença significativa, com 
destaque para as universidades particulares confessionais especialmente as regidas pela Igreja Católica. Durante o século XX, como afirma Cunha (2007), o ensino superior passa por uma fase de grande crescimento quantitativo, momento em que também se discute a modernização do sistema.

O aumento da população atendida no ensino superior vem ocorrendo de forma significativa desde então, principalmente pela expansão do setor privado, que intensificou-se em dois momentos: nos anos de 1970, durante os governos militares, e no final da década de 1990 (MINTO, 2006). Ao mesmo tempo, é necessário considerar que desde meados do século XX os avanços na ampliação do acesso à educação básica e superior foram resultados da pressão popular que demandava mais escolas básicas e de ensino superior. A opção política foi pela oferta de vagas privadas.

Na primeira década do século XXI manteve-se a expansão do ensino superior, como se lê no Relatório do 1 o ciclo de monitoramento das metas do PNE: biênio 2014-2016 “a TBM [Taxa Bruta de Matrícula] na graduação brasileira era de 18,6\% em 2004 e alcançou a marca de 32,1\% em 2014” (INEP, 2016, p. 272). Como se lê no referido relatório:

\begin{abstract}
A TBM é um indicador da capacidade de absorção do sistema educacional em determinado nível de ensino. É definida conceitualmente pelo total de matriculados (independentemente da idade) em relação ao total populacional em idade considerada adequada para cursar o nível de ensino em análise. O PNE considera a população de 18 a 24 anos como aquela que está na idade de referência para cursar a graduação. A TBM na graduação, portanto, indica, aproximadamente (sem considerar as vagas ociosas), qual é a capacidade de absorção de todos os cursos de graduação do país em relação ao tamanho da população de 18 a 24 anos de idade. (INEP, 2016, p .272-273).
\end{abstract}

Da mesma forma, manteve-se o crescimento pelo setor privado. Até o ano de 2014, e considerando a criação do Programa Universidade para Todos (PROUNI), as matrículas cresceram tanto no ensino superior privado quanto no público. Mas, entre os anos de 2014 e 2016 houve decréscimo em torno de 4,5\% no número total de matrículas da graduação nas universidades públicas e crescimento em torno de 3,5\% nas Universidades privadas.

Esses números indicam as consequências dos cortes dos orçamentos das Universidades e dos diferentes entes federativos (estados e municípios), que afetam, além da expansão da matrícula nas universidades públicas, também a estrutura dos campi e a relação ensino e pesquisa, como indicam Mancebo, Silva Junior e Schugurensky (2016).

As universidades públicas sofrem os impactos dos cortes no orçamento na fase mais recente de expansão do ensino superior, que compreende o período do primeiro mandato da ex-Presidente Dilma Roussef até o momento, de acordo com periodização proposta por Mancebo, Silva Junior e Schugurensky (2016). 
Para as Universidades privadas há que se considerar também o impacto do crescente desemprego. Dados da PNAD Contínua (IBGE, 2017) indicam que para os trimestres de jan/fev/março, entre os anos de 2014 até 2017, as taxas de desocupação no Brasil foram respectivamente: 7,2\% em 2014, 7,9 em 2015, 10,9 em 2016 e 13,7 em 2017. Diante do desemprego e em consequência da redução do poder de consumo, as Universidades privadas tomam medidas de ajuste ampliando a quantidade de alunos por professor, inclusive pela oferta de cursos à distância, reajustando jornadas dos professores e a contratação de pessoal técnico administrativo, o que pode comprometer a qualidade do ensino, pela sobrecarga de trabalho de professores e de tutores em $\mathrm{EaD}$, acentuada também se o docente é obrigado a ministrar aulas em várias e diferentes disciplinas para completar sua jornada e seu salário.

Nas Universidades Federais torna-se crítica a gestão do orçamento tendo em vista que o mesmo é regulado também pela quantidade de alunos. Para Mancebo, Silva Junior e Schugurensky (2016, p. 212)

\footnotetext{
Nas instituições de educação superior públicas, o movimento de expansão de matrículas e cursos - como foi o caso do REUNI -, verificado pelo menos até 2013, é refreado em função dos ajustes, deixando às instituições a amarga tarefa de reconfigurar diversos procedimentos internos, para fazer frente à expansão (do período anterior) que lhes legou mais alunos, cursos, campi e forte interiorização, sem o devido financiamento. A estratégia mais imediatamente observada é a dos cortes de verbas de manutenção e renovação, abandonando a infraestrutura física dos campi.
}

O corte de verbas para manutenção dos campi, pode também resultar em dificuldades para que as universidades realizem ensino, pesquisa e extensão. Mancebo, Silva Junior e Schugurensky (2016, p. 212-213) também indicam que outra consequência dos cortes é a ênfase no ensino, em detrimento da pesquisa, além da evasão como reação a precarização das condições de oferta.

No ensino superior privado chama a atenção o problema das vagas ociosas, que não é novo, mas que se acentua entre os anos de 2014 e 2015, quando aumentaram de 1.525 .052 para 2.188.653 (INEP, 2014; 2015), ou seja, algo em torno de 43\%, enquanto que nas instituições públicas observou-se uma sensível queda, de 177.187 para 174.136 (INEP, 2014; 2015), conforme dados das Sinopses da Educação Superior.

A pesquisa também sofre os impactos dos cortes nos orçamentos das universidades, uma vez que a sua realização demanda, além de pessoal, equipamentos e laboratórios. Quando realizada junto aos agricultores familiares, também exige o deslocamento dos até locais distantes dos campi, que pode ser impedido ou dificultado, pois carros e combustível, também são objetos dos cortes. 
A realização de pesquisas nas Universidades depende também do acesso aos financiamentos das agências federais e estaduais de fomento à pesquisa e das bolsas. Tanto governo federal como os estaduais estão cortando os orçamentos para ciência tecnologia, colocando em risco não apenas o funcionamento das universidades, mas o próprio futuro do país. O governo Federal, em março deste ano cortou em $44 \%$ o orçamento de ciência e tecnologia, que atingiu o patamar mais baixo dos últimos doze anos - 2,8 bilhões de reais. $\mathrm{O}$ corte de $44 \%$ na pasta é dramático pois se dá sobre um orçamento que já vem sendo reduzido anualmente, desde 2013 conforme Petherick (2017).

Outra possibilidade que vem sendo historicamente estimulada pelas políticas científicas e tecnológicas, é o investimento privado em pesquisa. Em 2016 foi aprovado o novo marco legal da pesquisa que regula a relação entre universidades e empresas. Esse é o tema que será tratado a seguir.

\section{O aprofundamento das contra reformas e as consequências para a realização de ciência e tecnologia nas Universidades}

[...] em função dos cortes do governo federal. Pois a universidade passa por momento difícil e o prédio tem manutenção cara. Além disso, as prefeituras da região estão também quebradas. $\mathrm{O}$ atual prefeito tem muita vontade de colaborar para resolver os impasses, mas também não tem dinheiro, Há diversos parceiros que colaboram conosco, fazemos muitas coisas juntos, mas recurso ninguém tem. (Pesquisadora brasileira).

No dia 11 de janeiro de 2016, ainda no governo de Dilma Roussef, aprova-se o novo marco legal da Ciência e Tecnologia, a Lei no. 13.243/2016 (BRASIL, 2016). Entre outros objetivos, a nova Lei pretende eliminar os entraves existentes na complexa legislação anterior, que dificultava a realização de pesquisas junto às empresas, estimulando as instituições públicas de pesquisa, especialmente as universidades e seus pesquisadores, em atividades de inovação junto às empresas. Nesse sentido, o novo marco legal não cria nada de novo, regulamenta práticas já existentes num só marco legal, pretendendo, com isso, a segurança jurídica.

A Lei 13.243/2016 prevê o compartilhamento de instalações entre instituições de pesquisa e empresas, a possibilidade de os pesquisadores receberem retribuições pecuniárias por parte das empresas envolvidas, prevê acordos em parcerias de pesquisa e inovação por meio dos quais as instituições podem negociar as patentes, entre outros aspectos. 
Em termos de tendências nas políticas científicas e tecnológicas, com a Lei 13.243/2016 mantém-se o que vem se desenhando desde que o país, no pós-guerra, assumiu a importância desse campo como estratégico para o desenvolvimento nacional. Ou seja, mantém-se a tentativa de aproximar empresas e instituições de pesquisa, além de aumentar o investimento privado em pesquisa e desenvolvimento (P\&D), como já se observou no caso da criação dos Fundos Setoriais e no lugar que assumiu a inovação tecnológica na política de ciência e tecnologia (Lei da Inovação 10.973/2004). No entanto, o investimento privado em $\mathrm{P} \& \mathrm{D}$ não tem se realizado nem no ritmo, nem no volume desejado.

É o que sugere, por exemplo, estudo recente realizado por Soares et al. (2016, p. 714) com o objetivo de caracterizar o sistema de inovação brasileiro. Os autores fundamentam sua análise no conceito de sistema de inovação, considerando-o à partir do modelo da tríplice hélice, da seguinte forma: "No modelo da hélice tríplice, proposto por Etzkowitz e Leydesdorff (1996), a interação entre universidade, governo e indústria oferece um ambiente inovador resultante de iniciativas nessas três esferas institucionais (acadêmica, pública e privada), proporcionando assim o desenvolvimento econômico baseado no conhecimento." (SOARES, et al. 2016, p. 714). Em relação aos investimentos privados em P\&D, até 2013 não haviam sido atingidos os indicadores pactuados no Plano de Ação em Ciência, Tecnologia \& Inovação 2007-2010. Como indicam Soares et al. (2016, p. 716) esse investimento "deveria passar de 0,49\%, em 2006, a 0,65\%”. Até 2013 não havia sido cumprida a meta. Nem mesmo a criação da Estratégia Nacional para Ciência, Tecnologia e Inovação alterou esse quadro:

Era esperado que até 2014 o país tivesse investido 1,8\% do seu PIB em P\&D, sendo metade desse montante ( $0,9 \%$ do PIB nacional) aplicado por empresas. [...]. A quota de mercado das empresas brasileiras nos investimentos em P\&D (de tendência decrescente desde 2005, quando atingiu 52,3\%) representava, em 2013, apenas $42,3 \%$ das despesas totais [...] (SOARES et al., 2016, p. 716).

Esses indicadores negativos do investimento privado em P\&D já haviam sido apontados por Bagattolli (2008, p. XVI) que, utilizando-se dos resultados da Pesquisa de Inovação Tecnológica (PINTEC) afirmava que:

[...] outras evidências empíricas relativas ao cenário nacional e internacional sugerem a escassa probabilidade de uma alteração dessa situação. Entre elas, a importância que tem a realização de $P \& D$ na estratégia de inovação das empresas inovadoras [brasileiras]: quatro vezes menor do que a aquisição de máquinas e equipamentos.

Informações mais recentes obtidas em matéria veiculada pela Confederação Nacional da Indústria (CNI, s/d), sugerem a continuidade dessa tendência das empresas brasileiras em 
investirem pouco em $\mathrm{P} \& \mathrm{D}$, tendo em vista a redução do investimento privado para $0,42 \%$ do total, acrescentando ainda que:

\begin{abstract}
No subfator Capacidade de Inovação, o país está na penúltima posição, à frente apenas do Peru. Em Gastos de P\&D nas empresas, o Brasil é o nono de 16 avaliados, com investimentos que representaram $0,42 \%$ do Produto Interno Bruto (PIB). A título de comparação, na Coreia do Sul o esforço realizado pelo setor privado em $\mathrm{P} \& \mathrm{D}$ coloca o país em primeiro lugar no ranking, com gastos que representaram $3,36 \%$ do PIB.
\end{abstract}

As empresas brasileiras, quando investem em $\mathrm{P} \& \mathrm{D}$, o fazem para inovação de processos, mais do que em produtos, como indicam também Soares et. al (2016). A baixa propensão do empresariado brasileiro em investir em Inovação deve ser entendida como uma resposta racional e pragmática das empresas aos sinais do mercado (BAGATTOLLI, 2008). Ou seja, esse investimento não se mostra lucrativo diante da competitividade internacional, dos exigentes mercados de consumo, do preço do dinheiro, e dos ganhos que podem ser obtidos com maior facilidade e rapidez apenas com a transferência tecnológica.

A par desta tendência, a Lei de Inovação parece ter reforçado o papel da Universidade na produção de ciência, tecnologia e inovação, como também sugerem Soares et al. (2016, p. 714) ao observarem a "[...] intensificação na academia de atividades relacionadas à proteção de propriedade intelectual e transferência de tecnologia para a indústria". A leitura de Soares et al. (2016, p. 714) sugere também que se fortaleceu o papel das universidades na criação de patentes. Dentre os pedidos de patentes feitos por residentes no país cresceu a quantidade daqueles originados nas Universidades "que representaram em 2013 aproximadamente 15\% do total". Ressalte-se que no Brasil a maior porcentagem de pedidos de patentes são de origem estrangeira: "Em 2013, por exemplo, o percentual de pedidos de patentes de origem estrangeira no país foi de 76,6\% (26.075 dos 34.050 pedidos) (MCTI, 2016)" (SOARES et al. 2016, p. 714).

Ou seja, a Universidade é lugar privilegiado, no Brasil, para realização de pesquisa e inovação. Nesse sentido, outro aspecto que se mantém no novo marco legal é a característica ofertista-linear, ou seja, da oferta de pesquisa das universidades para as empresas, uma vez que, pela forma como é sugerida na Lei, a infraestrutura, o pessoal e o conhecimento se localizam nas universidades e instituições de pesquisa e não nas empresas.

Mas, no momento atual é pouco provável que as universidades possam contar com investimentos das empresas para realização de pesquisas e inovação. Ou seja, a realização de pesquisas nas universidades públicas brasileiras dependem basicamente do investimento público. O cenário, nesse sentido é desalentador tendo em vista a aprovação da Emenda 
Constitucional no. 95 de 15 de dezembro de 2016 (BRASIL, 2016), que institui o novo regime fiscal, congelando por vinte anos os gastos do governo federal.

De um modo geral, nas políticas de ciência, tecnologia e inovação, também prevalece a ideia de produção de conhecimento numa visão schumpeteriana, ou seja, de indução ao desenvolvimento econômico. Trata-se de impulsionar o componente técnico científico do desenvolvimento.

Nesse sentido, vale retomar a crítica de Dagnino (2015) quando considera que não se trata de negar o processo técnico científico e nem o desenvolvimento, mas da insuficiência de se considerar esse processo desconectado da luta de classes e da divisão internacional do trabalho. $\mathrm{O}$ autor, retomando a origem da ideia de sociedade do conhecimento relembra que na década de 1950 o termo "economia do conhecimento" serviu para demonstrar que o crescimento econômico era cada vez mais resultado do conhecimento (o resíduo de Solow).

Dagnino (2015) relembra ainda que o componente técnico científico já havia sido muito antes identificado por Marx, no trabalho vivo, mas considerando-o na dinâmica da produção capitalista, na extração da mais valia. Nesse sentido, a tecnociência é fundamental para manutenção e expansão do modo de produção capitalista.

Essa concepção é tomada de forma equivocada pelos adeptos da economia da inovação, inspirados por Schumpeter, conferindo naturalidade à forma como se entende, desde então, o conhecimento como força produtiva. Como afirma Dagnino $(2015$, p. 2) " $Y$, también, al conferirle un carácter progresivo - de positividad intrínseca asociada al valor del conocimiento -, asegurar, legitimando y naturalizando, su hegemonía".

Diante da crise estrutural do capital tornam-se evidentes esses limites, especialmente se considerados da perspectiva dos países da América Latina. A dinâmica tecnocientífica que orienta a produção de conhecimento ao capital é liderada pela ciência hegemônica, monopolizada pelos países centrais e pela sociedade a ela acoplada, como sugere Dagnino (2015).

\section{Pós-graduação, extensão e classes populares: uma equação complexa.}

Se [...] é uma metragem quantitativa, onde a quantidade de papers é uma coisa que tem mais valor que o impacto social que a pesquisa trás, então os órgãos avaliadores certamente não te avaliam tão bem. Então, a minha pesquisa é aplicada e vira uma extensão quando isso gera um resultado em que eu consigo minimizar problemas locais e isso pra mim está supervalorizado... Valorizado pelos povos tradicionais com quem eu trabalho. Então, a questão é: valorizado por quem?

(Pesquisadora brasileira) 
Apesar de evidentes os limites ao desenvolvimento, uma visão econômica sobre o conhecimento e a pesquisa científica permeia as Universidades, alimentada também, pelos padrões que orientam a avaliação da relevância das pesquisas, dos cientistas e dos programas de pós-graduação nos quais atuam. É o produtivismo acadêmico, que mede a qualidade da pesquisa e inovação, em quantidade de artigos científicos publicados em periódicos indexados e de reconhecimento internacional. Trata-se de um mecanismo que privilegia quantidades de pontos, de citações, de publicações em revistas melhor classificadas, que uniformizam avaliações de desempenho individual de pesquisadores e a avaliação de programas de pósgraduação.

A avaliação, motivada muito mais pela necessidade de estabelecer critérios para distribuição de orçamento, mais curto do que a quantidade de programas de pós graduação, instala e reforça a competitividade, embora pretenda a qualidade. Este é um ponto bastante crítico em tempos de cortes nos orçamentos do governo Federal.

Tornam-se cada vez mais claros os nexos entre produtivismo e privatização do conhecimento, ainda que seja inegável o resultado desse processo, que induziu a produção bibliográfica e a consequente divulgação da ciência brasileira. Um desses nexos, por exemplo, pode ser identificado nos índices de citação, com indica Zingano (2017, p. 121):

\begin{abstract}
Com efeito, pode-se observar que a política intransigente dos índices de citação, controlados pelo ISI e pelo JCR, atualmente propriedades da Thomson Reuters, leva não somente a uma dependência da produção em língua inglesa - e das agendas que eles estabelecem -, mas também tem claro interesse econômico, pois esses índices provêm de companhias privadas, cuja lógica em última instância é o lucro. Isso é claramente inquietante, pois não somente estamos fazendo um esforço público e gratuito para promover o conhecimento e a discussão, como também corremos o risco de ter de mercantilizar nossa produção — seja cobrando pelos artigos, seja dependendo da aceitação em bases privadas, orientadas pelo lucro, para poder recorrer a fundos públicos de apoio à publicação.
\end{abstract}

O produtivismo contribui também para tornar consensuais determinados modelos de atividade científica, que podem não informar sobre a relevância da pesquisa, refletindo muito mais, como também alerta Boron (2008, p. 31), "la asimetria de poder existente entre aquellas teorizaciones que articulan los intereses de las clases dominantes (y las naciones dominantes en el sistema imperialista) y las que representan al pensamiento crítico".

O reducionismo trazido pelos critérios de mercado, que o autor denomina de barbárie economicista, a adequação aos modelos e controles internacionais, pode trazer empobrecimento para a pesquisa em ciências sociais, relacionadas, de acordo com Boron (2008, p. 81) "al individualismo metodológico que, en consonância con las premisas de la 
economía neoclásica, consagran a la desaparición de los actores colectivos (no por casualidad las clases sociales, los sindicatos, las organizaciones populares, etc.)".

Os pesquisadores que inspiram esse ensaio, na contracorrente dos modelos científicos hegemônicos impostos pelos critérios de avaliação e financiamento da pesquisa, optaram pelos coletivos. Esse é o tema que será tratado a seguir.

\section{A relação entre a Universidade brasileira e as classes populares.}

E realmente essa questão de fazer pesquisa com os pobres. Assim é denominado. [...] o que a gente pode chamar de inclusão, mas aqui é fazer pesquisa com pobre.

As pesquisas são direcionadas. São pesquisas a respeito de patenteamento aqui é muito grande. São voltadas mais para isso. Então, toda vez que se fala em projeto que você pretende desenvolver um, para inclusão social, é entendido como filantropia. Sabe por que? Existe uma teoria econômica, uma teoria de sociedade que o motor da sociedade são as empresas. [...] para os mais pobres, é assistencialismo, são políticas compensatórias, Bolsa família [...], a pesquisa ela tem uma direção mercadológica. (Pesquisadora brasileira).

Apesar das tendências reducionistas nas Universidades, a escolha por atuarem junto à classes populares feita pelos pesquisadores entrevistados, assim como de muitos outros em universidades brasileiras e Latino Americanas, indica que essa instituição resiste. Mantém-se viva como espaço de possibilidades e alternativas, inclusive aquelas que escapam às tendências produtivistas e privatistas. Permitem questionar, por exemplo, o diagnóstico de disfuncionalidade feito por Dagnino (2015), segundo o qual a Universidade não tem importância, tanto no que se refere à produção de conhecimentos exigido pelo capital, quanto para a população que sofre as consequências do processo de sua ampliação. Ao longo do tempo, a universidade brasileira, perdeu o lugar de produtora de conhecimentos para a elite dirigente. Essa disfuncionalidade se acentuou junto com o abandono definitivo do projeto nacional, ocorrida na década de 1990.

Para Leher $(2015$, p. 14) a Universidade na América Latina ainda tem um papel a cumprir como engrenagem do capital e na formação adaptada:

Dada a forma específica de inserção da América Latina na economia-mundo esse padrão de acumulação irá requerer, crescentemente, o apoio da universidade. Entretanto, longe de serem acordos virtuosos que possam contribuir para o fortalecimento da autonomia universitária, da educação omnilateral e da pesquisa original, comprometida com os grandes problemas dos povos, esses contratos e acordos têm como pressuposto que a universidade deve ter uma função de suporte, de prestadora de serviços materiais e, não menos importante, uma função simbólica, relacionada à governabilidade da ordem social.

Ambos os diagnósticos encontram suporte tanto nas políticas de ciência e tecnologia aqui indicadas quanto nos depoimentos. É preciso considerar que as demandas das classes populares por educação superior não se resumem à busca de certificação. Incluem o direito à 
apropriação autônoma e autocentrada da cultura, dos conhecimentos historicamente produzidos, que formam sujeitos (MONFREDINI, 2016). Esse direito pressupõe uma universidade em que a produção de conhecimento e sua circulação também se realizem como bem público, compartilhado entre os envolvidos.

Nesse sentido, considera-se que a relação com as classes populares pode se constituir como uma alternativa à ressignificação social da universidade brasileira, como argumenta-se na sequência.

\title{
A atuação junto à cooperativas e movimentos sociais como alternativa
}

\begin{abstract}
Porque aí cabe a gente olhar para o nosso país e falar assim "O que que a gente quer? Como a gente quer?" Porque o governo federal financia violentamente pesquisa no Brasil, com bolsas, editais, financiando projetos. Por que não dizer que esse dinheiro pode ser também para pessoas que querem, [...] fazer linhas de pesquisa com uma forte inserção social para solucionar problemas locais e regionais? (Pesquisador Brasileiro)

2012 meu projeto foi aprovado, também foi para mim uma grande vitória, porque também foi o primeiro projeto que eu mandei e numa área que eu gosto de atuar e de trabalhar que é a agroecologia. Dentro de movimentos sociais, trabalhar com quem realmente precisa. [...] Eu acho que é mais importante, eu me vejo enquanto profissional mais realizada. (Pesquisadora Brasileira).
\end{abstract}

Apesar da crise em curso, nas Universidades mantém-se viva a utopia de muitos daqueles que fazem essa instituição: a de que se mantenha a sua característica essencial que é o pensar como base da sua (re)criação.

A par do produtivismo e da privatização, nesse início de século XXI nota-se a criação de políticas públicas de ensino superior, ciência e tecnologia, tanto para incluir nesse nível de ensino grupos historicamente excluídos, como para aproximar Universidade e Sociedade, a partir das necessidades da população.

A inclusão no ensino superior de negros, indígenas, além dos jovens pobres, com renda familiar de até três salários mínimos foi resultado da criação da Lei de Cotas (Lei no 12.711, de 29 de agosto de 2012), do Programa Universidade Para Todos (PROUNI - Lei $\mathrm{n}^{\circ} 11.096$, de 13 de janeiro de 2005) e do REUNI (Decreto 6096 de 24 de abril de 2007).

Em consonância com essas políticas, em 2007 foi criado o quesito Inserção Social na avaliação da pós-graduação, como mais um indicador da qualidade dos programas. A Inserção Social tem sido definida pelas áreas ao longo desses dez anos, mas sua criação é significativa, pois compõe, junto com outras, um conjunto de políticas de ciência, tecnologia e de ensino superior criadas nesse período, nas quais se identifica a perspectiva de considerar as classes historicamente excluídas no Brasil. 
No documento elaborado pelo então Diretor de Avaliação Renato Janine Ribeiro para explicar o novo quesito, lê-se que:

Essa inovação é muito importante, porque significa o reconhecimento oficial, pela Capes, de que a pós-graduação tem uma responsabilidade social e deve assim, não apenas melhorar a ciência, mas também melhorar o país e, por que não? Sobretudo se pensarmos em termos de ecologia e meio ambiente, o mundo. (RIBEIRO, 2007).

Apesar da grande polêmica provocada pelo documento, junto com Boufleuer (2009, p. 372) entende-se que o quesito Inserção Social traz "um novo olhar a ser lançado sobre a pósgraduação stricto sensu do país, no sentido da verificação de sua presença e do seu impacto na e sobre a sociedade."

O esforço para definir a Inserção Social em cada área e programa de pós-graduação exigiu, e ainda exige, que os pesquisadores pensem sobre o que não é tão óbvio - que o fazer ciência, e o seu resultado, não são, em si mesmos, percebidos como relevantes, pela sociedade. Boufleuer (2009, p. 377) aponta para esse aspecto:

Enfim, a tematização da inserção social pode ser vista como uma reação por parte da política pública a essa postura asséptica da pós-graduação em relação à sociedade, induzida, talvez, pelo próprio processo de avaliação. Com a criação do quesito inserção social se começa a sugerir que o reconhecimento acadêmico do pesquisador pelas suas conquistas implica, de alguma forma, a capacidade de comunicar ou de fazer valer seus "achados" junto à sociedade.

O quesito Inserção Social contém um forte componente de articulação com a extensão. Da perspectiva aqui tratada, pode estimular, com o tempo, a relação dos pesquisadores com movimentos sociais, cooperativas e outras organizações. Mas, seu valor na ficha de avaliação dos programas, ainda é relativamente baixo, entre 10 a $20 \%$, de acordo com a área e se é acadêmico ou profissional.

No campo das políticas de ciência, tecnologia e extensão vale destacar também a criação do Programa Pró-Extensão (PROEXT) e da Secretaria de Ciência e Tecnologia para Inclusão Social (SECIS), ambos em 2003. Com o PROEXT o governo federal institucionalizou o fomento à projetos de extensão universitária. A existência de uma política pública de fomento à extensão representou, na consideração de Santos e Deus (2014), um “divisor de águas", tendo em vista, que tradicionalmente é desvalorizada em relação à pesquisa e ao ensino.

Outro divisor de águas no campo das políticas de ciência e tecnologia, foi a criação da SECIS. Com a nova Secretaria, o então Ministério da Ciência, Tecnologia e Inovação (MCTI), (agregado em 2016 ao Ministério das Comunicações pela lei 13.341/2016), pretendeu imprimir uma mudança nas políticas de ciência e tecnologia brasileiras com o objetivo de promover o desenvolvimento social estimulando a produção científica voltada 
para as populações historicamente excluídas, indicado tanto a criação e difusão de conhecimentos pela Universidade, voltados para as classes populares, como o apoio para divulgar e transformar em tecnologias e "patentes" os conhecimentos, saberes e técnicas geradas na prática, por trabalhadores rurais, pequenos proprietários e suas famílias, os sem teto e moradores das favelas urbanas, propiciando desenvolvimento econômico e social a essas populações.

O aprofundamento das contra reformas ameaçam severamente tanto esse conjunto de políticas públicas, como os seus resultados, que mal começam a ser notados, motivo pelo qual torna-se relevante retomar temas aparentemente superados, entre eles, o da relação entre universidade e classes populares, que agora estão dentro, e não apenas, fora dos seus muros. Para a Universidade, como afirma Leher (2015, p. 14) “por mais débeis que sejam os laços dos setores acadêmicos com as lutas sociais, é certo que o futuro da universidade pública latino-americana dependerá, fortemente, do avanço desses nexos virtuosos entre a universidade e as lutas anti-imperialistas e anticapitalistas".

Este tema emergiu nos depoimentos dos pesquisadores brasileiros, sugerindo que na universidade brasileira, apesar do ininterrupto processo de privatização, práticas comprometidas com as classes populares acontecem, especialmente com associações e cooperativas. Tais práticas se realizam e se mantém com dificuldade, pois não são essenciais ao cumprimento dos critérios produtivistas.

Diante dos evidentes reducionismos de mercado que vão se instalando no âmbito das políticas e das práticas na Universidade brasileira, é possível afirmar que esta opção se estabelece como alternativa.

Entende-se a alternativa no movimento de mudança histórica que se realiza nas contradições e nas disputas que permeiam a Universidade, as políticas de ensino superior, de ciência e tecnologia, e o lugar que o Brasil ocupa na divisão internacional do trabalho.

A atuação junto à classes populares, especialmente cooperativas e movimentos sociais, pode ser considerada uma alternativa em primeiro lugar porque a criação científica e tecnológica é orientada para outro horizonte, contrário ao da lógica schumpeteriana em que a tecnociência, pensada da perspectiva do capital, impulsiona o desenvolvimento para uma sociedade competitiva e individualista, na qual alguns poucos se beneficiam do resultado econômico, privadamente. Ao contrário, os pesquisadores buscam, nesses casos, desenvolver tecnologias sociais.

De acordo com Thomas (2009, p. 26), as tecnologias sociais proliferam desde a década de 1960, e o seu objetivo "tem sido responder à problemática de desenvolvimento 
comunitário, de geração de serviços e de alternativas tecnoprodutivas em cenários socioeconômicos caracterizados por situações de extrema pobreza [...]."

A definição que tem sido adotada para tecnologias sociais aponta para a valorização do conhecimento das classes populares e da sua interação com a universidade. De acordo ainda com Thomas (2009, p. 27), a tecnologia social pode ser definida como "uma forma de criar, desenvolver, implementar e administrar tecnologia orientada a resolver problemas sociais e ambientais, gerando dinâmicas sociais econômicas de inclusão social e de desenvolvimento sustentável.

As tecnologias sociais pressupõem processos vivenciados por todos os envolvidos, alunos, professores, e as classes populares. Ou seja, induzem a universidade a considerar a capacidade da população historicamente excluída de gerar ou adaptar conhecimentos e processos de forma autodeterminada. Autodeterminação é aqui considerada com base em Mészáros (2007).

Nesse sentido, a relação entre os pesquisadores, movimentos sociais e cooperativas pode criar espaços alternativos, em que a formação esteja voltada para outro projeto societário.

Atuar junto a essas organizações sociais que agregam as classes populares, indica uma vertente oposta à competitividade que se realiza nos atuais processos de privatização das Universidade e de avaliação a ele atrelado.

Nas cooperativas, por exemplo, outros valores permeiam as práticas: a livre associação, o trabalho cooperativo, a solidariedade, as decisões democráticas e compartilhadas, a remuneração do trabalho e não do capital ${ }^{5}$. Para Singer (2003), trata-se de outra economia, a solidária.

Mas, essa atuação conjunta realiza também a negação de suas possibilidades. No caso da organização cooperativa, por exemplo, no conflito entre o que se propõe como fim - a apropriação coletiva dos resultados por parte dos cooperados - e as forças do mercado. Nesse sentido, as cooperativas historicamente crescem nas crises, como saída precária e temporária ao desemprego, expondo os cooperados à desregulamentação dos direitos trabalhistas e, ainda, deslocando a responsabilidade das políticas públicas do Estado, para a sociedade civil como indica Paniago (2008).

5 São inúmeras as dificuldades encontradas pelas associações e cooperativas para sua manutenção, relacionadas à precariedade das condições de vida das classes populares. As universidades também atuam na perspectiva de pensar conjuntamente encaminhamentos a essas dificuldades. Mas a análise desses aspectos foge ao objetivo deste artigo. 
Ao mesmo tempo as cooperativas carregam um potencial educativo importante para a experiência coletiva de sociabilidades alternativas. Como afirmam Frantz, Schönardie e Schneider (2017, p. 17):

[...] a noção de organização cooperativa é mais ampla que uma simples instrumentação técnica. Tem também uma dimensão política vinculada aos interesses do trabalho das pessoas. A organização cooperativa nasce de um movimento social que traz em seu bojo histórico a questão da valorização do trabalho humano (VESTER, 1975). Trata-se, portanto, também de um movimento político que constitui a identificação, a associação e a comunicação -entre os que trabalham- como seus instrumentos de atuação, de interação. Como tal, a organização cooperativa também pode ser definida como um lugar de educação política ao levar os seus integrantes à comunicação e ao debate sobre os valores, os interesses e os objetivos da cooperação.

Dessa perspectiva constitui-se numa alternativa para que pesquisadores e alunos possam criar experiência coletiva de autodeterminação, de relações democráticas, de valorização de conhecimentos diversos, recriando a própria Universidade que historicamente se institui como lugar da "Verdade". É Dagnino (2015, p. 15) que explicita o potencial contido nessa relação, com a ideia de ex vestigação:

[...] que sería construir conocimiento en conjunto con estudiantes y movimientos sociales "para fuera" y no "para dentro" del mundo de la universidad y de la ciencia como lo hemos hecho hasta ahora. Ese proceso sería problem oriented y policy oriented, y no orientado por disciplinas o simplemente para conocer sin comprometernos con el cambio. (grifos nossos).

Aqueles que já atuam nesse sentido enfrentam entraves dentro das universidades. A atuação dos pesquisadores entrevistados junto à cooperativas e movimentos sociais vai se estabelecendo lentamente, ao longo de décadas, tendo em vista as inúmeras dificuldades que se apresentam, dentre elas: construir relações de confiança; as diferenças entre os tempos da universidade, das cooperativas e associações; as distâncias, especialmente quando se tratam de cooperativas no meio rural; as precárias condições das cooperativas e associações que provocam descontinuidades materiais e humanas; a falta de recursos materiais e humanos, também nas universidades; a descontinuidade nas políticas de financiamento, entre outros. Além disso, internamente, nas universidades, os pesquisadores estão submetidos às mesmas exigências produtivistas que reforçam o sentido privatista da produção do conhecimento. Manter essa vertente de trabalho que aposta em formas coletivas e que agrega as classes populares, exige que o pesquisador se desdobre entre duas lógicas diferentes: a privatista que se instala com toda a força do mercado e do desmonte das políticas sociais; e a pública que tende ao desaparecimento, caso pesquisadores como os entrevistados e classes populares, não insistam, ampliando social e politicamente essas experiências, para não serem capturados pelas aparentes "inclusões" existentes tanto nas universidades como fora delas. 
Nas universidades, por exemplo, incluir-se no competitivo mercado dos rankings nacionais e internacionais, reduzindo o sentido da pesquisa aos resultados publicáveis. No campo, o abandono da agricultura pelo trabalho precário nas cidades ou no agronegócio.

Como alerta Bringel (2010) essa relação entre universidades e movimentos sociais envolve problemas que surgem no esforço de descolonizar e repensar a produção de conhecimentos, especialmente das ciências sociais, o que significa incorporar os diálogos com vários atores sociais, em diferentes enfoques, pressupondo a produção conjunta de conhecimento.

Nesse aspecto, é importante, aqui retomar análise anterior (MONFREDINI, 2016), na qual se ressalta que os pesquisadores da área da agroecologia tem invertido a hierarquia do modelo científico hegemônico que tradicionalmente valoriza a pesquisa em detrimento da extensão, ao atuar junto aos agricultores familiares, por meio da extensão, realizando a partir daí, a pesquisa. Nesse processo, não só as pautas de pesquisa são orientadas de fora para dentro da Universidade, alimentando linhas de pesquisa, mas também conhecimentos novos são inseridos de fora para dentro.

As ações desenvolvidas em conjunto por pesquisadores e classes populares, organizadas em cooperativas e movimentos sociais, em que o poder de decisão é compartilhado, geram experiências comuns, democráticas.

É possível afirmar que a realização de ciência e tecnologia junto com as classes historicamente excluídas é importante para que a universidade brasileira possa recriar-se. Mas, como todo processo que se realiza no âmbito da nossa história lenta como a denomina Martins (2011) referindo-se aos processos de modernização que acontecem sobre a manutenção das formas históricas irresolutas; essa alternativa tem se realizado como resistência nas Universidades brasileiras e enfrenta obstáculos para disseminar-se.

Apesar da diversidade que caracteriza as universidades brasileiras, provavelmente, nessas instituições, prevalece o distanciamento entre pesquisadores e as classes populares, tendo em vista as tendências reducionistas impostas pelos processos de privatização e pelo produtivismo; associados à cultura autoritária, legado das relações escravocratas que ainda povoam o imaginário de brasileiros e brasileiras, também nas universidades. Acrescente-se ainda o curto período de tempo de criação do PROEXT, da SECIS e do quesito inserção social, políticas que, ao contrário, estimulam a relação entre a universidade e as classes populares. 
Nesse sentido, é importante a manutenção e ampliação dessas políticas tendo em vista o seu efeito indutivo na relação entre Universidade e classes populares e, indiretamente, para a (re)criação da primeira.

\section{Conclusões}

A intenção neste ensaio foi a de pensar a Universidade colocando em foco, contraditoriamente nesse momento crítico, uma alternativa. Apenas uma das inúmeras que certamente se desenham no cotidiano dessa instituição.

O principal objetivo foi tratar da relação entre Universidade brasileira e classes populares como uma alternativa que tem sido construída por pesquisadores, cooperativas e movimentos sociais, procurando evidenciar as possibilidades que ela traz para a Universidade. Pensada na situação crítica em que se encontra o país, e diante do desmonte de políticas públicas conquistadas recentemente, essa alternativa ganha força na perspectiva da resistência necessária.

Ganha força também, pois aponta para a possibilidade de que as classes populares além de acessarem o ensino superior, também se apropriarem de forma autodeterminada dos conhecimentos produzidos historicamente.

Situações limites como a atual cobram ação. Os depoimentos dos entrevistados inspiram a pensar em uma das ações possíveis.

Em meio ao aprofundamento das contra reformas que facilitam a ampliação e aprofundamento das taxas de exploração, trazendo mais miséria e sofrimento humano, vale a pena, para encerrar, retomar Arroyo em texto de 2003 (p. 28), no qual o autor se pergunta "o que temos a aprender dos movimentos sociais?" para então repensar as teorias pedagógicas à partir dos "vínculos tensos entre trabalho e educação". Para Arroyo (2003, p. 31) o potencial inspirador dos movimentos sociais para o fazer educativo consiste em que

\footnotetext{
[...] nos puxam para radicalizar o pensar e fazer educativos na medida em que nos mostram sujeitos inseridos em processos de luta pelas condições elementaríssimas, por isso radicais, de viver como humanos. Nos propõem como tarefa captar as dramáticas questões que são vividas e postas nessas situações limite e revelá-las, explicitá-las. E ainda captar como os sujeitos se formam, entrando eles mesmos como totalidades nos movimentos.
}

Decorridos pouco mais de dez anos da implementação do conjunto de políticas elencadas neste texto, as análises de Arroyo ecoam com mais força, tendo em vista o desafio a todos os acadêmicos, nesse momento crítico. 
A alternativa analisada neste ensaio funda-se em práticas democráticas, de respeito aos diversos conhecimentos e à população historicamente excluída, e na perspectiva de outro projeto societário que exige outra Universidade, em que o conhecimento seja fator de desenvolvimento sustentável, voltado para os seres humanos e a natureza. Portanto, público, compartilhado e acessível a todos. Os pesquisadores entrevistados evidenciam com seus depoimentos essa possibilidade que se realiza, a despeito dos reducionismos impostos pelos processos privatizantes do conhecimento e da Universidade.

\section{Referências}

ANAMATRA. Associação Nacional dos Magistrados da Justiça do Trabalho. Nota pública reitera posição contrária ao projeto de reforma trabalhista. Brasília, jul. 2017. Disponível em: https://www.anamatra.org.br/imprensa/noticias/25460-entidades-reiteram-posicaocontraria-ao-projeto-de-reforma-trabalhista. Acesso em: 20 jul. 2017.

ARROYO, Miguel. Pedagogias em Movimento. O que temos a aprender dos movimentos sociais? Currículo sem Fronteiras, Portugal, v. 3, n. 1, p. 28-49, jan./jun. 2003. Disponível em: http://www.curriculosemfronteiras.org/vol3iss 1articles/arroyo.pdf. Acesso em: 21 fev. 2017.

BAGATTOLLI. Carolina. Política científica e tecnológica e dinâmica inovativa no Brasil. Campinas: UNICAMP, 2008.

BEHERING, Elaine Rosseti. Brasil em contra-reforma. Desestruturação do Estado e perda de direitos. 2. ed. São Paulo: Cortez, 2008.

BEHERING, Elaine Rosseti. Rotação do Capital e crise: fundamentos para compreender o fundo público e a política social. In: SALVADOR, Evilásio et al. (orgs.). Financeirização, fundo público e política social. São Paulo: Cortez, 2012. p. 153-180.

BORON, Atilio A. Consolidando la explotación. La academia y el banco Mundial contra el pensamiento crítico. Córdoba: Espartaco, 2008.

BOUFLEUER, José Pedro. Inserção social como quesito de avaliação da pós-graduação. In: Revista Educação Pública, Cuiabá, v.18, n. 37, p. 371-382, maio/ago. 2009. Disponível em: http://periodicoscientificos.ufmt.br/ojs/index.php/educacaopublica/article/view/488/418. Acesso em: 11 jul. 2017.

BRASIL. Ministério da Ciência, Tecnologia e Inovação. Secretaria Nacional de Ciência e Tecnologia para Inclusão Social (SECIS). 2003. Disponível em: http://www.mct.gov.br/index.php/content/view/78953.html. Acesso em: 1 fev. 2014.

BRASIL. Decreto 6096. Institui o Programa de Apoio a Planos de Reestruturação e Expansão das Universidades Federais - REUNI. 2007. Disponível em:

http://www4.planalto.gov.br/legislacao/portal-legis/legislacao-1/leis-ordinarias/2017-leisordinarias. Acesso em: 8 jun. 2014. 
BRASIL. Emenda Constitucional 5 de dezembro de 2016. Altera o Ato das Disposições Constitucionais Transitórias, para instituir o Novo Regime Fiscal, e dá outras providências. Brasília, 2016. Disponível em:

http://www.planalto.gov.br/ccivil_03/constituicao/emendas/emc/emc95.htm. Acesso em: 10 jul. 2017.

BRASIL. Presidência da República. Lei 13.467. Altera a Consolidação das Leis do Trabalho (CLT). 2017. Disponível em: http://www4.planalto.gov.br/legislacao/portal-legis/legislacao1/leis-ordinarias/2017-leis-ordinarias. Acesso em: 10 jul. 2017.

BRASIL. Lei 13.465. Dispõe sobre a regularização fundiária rural e urbana, sobre a liquidação de créditos concedidos aos assentados da reforma agrária e sobre a regularização fundiária no âmbito da Amazônia Legal; institui mecanismos para aprimorar a eficiência dos procedimentos de alienação de imóveis da União [...]. 2017. Disponível em:

http://www4.planalto.gov.br/legislacao/portal-legis/legislacao-1/leis-ordinarias/2017-leisordinarias. Acesso em: 10 jul. 2017.

BRASIL. Lei 13.452. Altera os limites do Parque Nacional do Jamanxim e cria a Área de Proteção Ambiental Rio Branco. 2017. Disponível em:

http://www4.planalto.gov.br/legislacao/portal-legis/legislacao-1/leis-ordinarias/2017-leisordinarias. Acesso em: 10 jul. 2017.

BRASIL. Lei 13. 341. Altera as Leis n os 10.683, de 28 de maio de 2003, que dispõe sobre a organização da Presidência da República e dos Ministérios, e 11.890, de 24 de dezembro de 2008, e revoga a Medida Provisória n o 717, de 16 de março de 2016. 2016. Disponível em: http://www4.planalto.gov.br/legislacao/portal-legis/legislacao-1/leis-ordinarias/2017-leisordinarias. Acesso em: 10 jul. 2017.

BRASIL. Lei 13.243.Dispõe sobre estímulos ao desenvolvimento científico, à pesquisa, à capacitação científica e tecnológica e à inovação [...]. 2016. Disponível em:

http://www4.planalto.gov.br/legislacao/portal-legis/legislacao-1/leis-ordinarias/2017-leisordinarias. Acesso em: 10 jul. 2017.

BRASIL. Edital PROEXT- 2016. Disponível em:

http://portal.mec.gov.br/index.php?Itemid=490id=12243option=com_contentview=article.

Acesso em: 15 maio 2015.

BRASIL. Lei 13.005 que aprova o Plano Nacional de Educação (PNE). 2014. Disponível em: http://www.planalto.gov.br/ccivil_03/_Ato2011-2014/2014/Lei/L13005.htm. Acesso em: 15 maio 2015.

BRASIL. Lei 11.096 que institui o Programa Universidade para Todos. PROUNI. 2003. [Disponível em: http://www.planalto.gov.br/ccivil_03/_ato2004-2006/2005/lei/L11096.htm. Acesso em: 7 set. 2013.

BRASIL. Lei 12.711. Dispõe sobre o ingresso nas universidades federais e nas instituições federais de ensino técnico de nível médio e dá outras providências. [Lei das Cotas]. 2012. Disponível em: http://www.planalto.gov.br/ccivil_03/_ato2004-2006/2005/lei/L11096.htm. Acesso em: 25/11//2013]. 
BRASIL. Lei 10.973. Dispõe sobre incentivos à inovação e à pesquisa científica e tecnológica no ambiente produtivo e dá outras providências. 2004. Disponível em:

http://www.planalto.gov.br/ccivil_03/_ato2004-2006/2005/lei/L11096.htm. Acesso em: 6 dez. 2009.

BRETTAS, Tatiana. Dívida Pública: uma varinha de condão sobre os recursos do fundo público. In: SALVADOR, Evilásio et al. (orgs.). Financeirização, fundo público e política social. São Paulo: Cortez, 2012. p. 93-122.

BRINGEL, Breno. Ativismo Transnacional. O estudo dos Movimentos Sociais e as novas Geografias Pós-coloniais. Estudos de Sociologia, Rev. do Progr. de Pós-Graduação em Sociologia da UFPE, Recife, v. 16, n. 2, p. 185-215, 2010. Disponível em: http://www.revista.ufpe.br/revsocio/index.php/revista/article/view/122. Acesso em: 27 fev. 2017.

CHESNAIS, F. A mundialização do capital. São Paulo: Xamã, 1996.

CONFEDERAÇÃO NACIONAL DA INDÚSTRIA (CNI). Agência Gestão CT\&I: Brasil perde posições em ranking de competitividade. Disponível em:

http://agenciacti.com.br/index.php?option=com_content\&view=article\&id=10120:brasilretrocede-em-tecnologia-e-inovacao-devido-a-reducao-de-

pad \&catid=163: gestao $\&$ Itemid=227. Acesso em: 26 jul. 2017

CUNHA, Luiz Antônio. A universidade reformada. O golpe de 1964 e a modernização do ensino superior. 2. ed. São Paulo: Editora UNESP, 2007.

DAGNINO, Renato. La Universidad latinoamericana del futuro que su sociedad esta construyendo. Cuestiones de Sociología, Buenos Aires, n. 12, 2015. Disponível em: http://www.cuestionessociologia.fahce.unlp.edu.ar/. Acesso em: 1 nov. 2016.

FIRMIANO, Frederico Daia. A ilegalidade do Estado e o colapso do neodesenvolvimentismo no Brasil. SER Social, Brasília, v. 18, n. 39, p. 584-609, jul./dez. 2016. Disponível em: periodicos.unb.br/index.php/SER_Social/article/download/21344/17532. Acesso em: 13 mar. 2017.

FRANTZ, Walter; SCHÖNARDIE, Paolo Alfredo; SCHNEIDER, José Odelso As Práticas do Movimento Cooperativo como Lugares de Educação. Revista de Didácticas Específicas, Recife, n. 16, p. 14-26, 2017. Disponível em: https://revistas.uam.es/didacticasespecificas/article/viewFile/7496/8359. Acesso em: 20 jul. 2017.

INSTITUTO NACIONAL DE ESTUDOS E PESQUISAS EDUCACIONAIS ANÍSIO TEIXEIRA (INEP). Relatório do 1o. Ciclo de monitoramento das metas do PNE: biênio 2014-2016. Brasília: Inep, 2016. Disponível em: http://portal.inep.gov.br/documents/186968/485745/RELATÓRIO+DO+PRIMEIRO+CICLO +DE+MONITORAMENTO+DAS+METAS+DO+PNE+-+BIÊNIO+2014-2016/0dc50e213a60-444b-b7f6-1f16b8e5591f?version=1.1 Acesso em: 20 jul. 2017. 
INSTITUTO NACIONAL DE ESTUDOS E PESQUISAS EDUCACIONAIS ANÍSIO TEIXEIRA (INEP). Sinopse da Educação Superior 2015. Brasília: Inep, 2016. Disponível em: http://portal.inep.gov.br/basica-censo-escolar-sinopse-sinopse. Acesso em: 13 jan. 2017.

INSTITUTO NACIONAL DE ESTUDOS E PESQUISAS EDUCACIONAIS ANÍSIO TEIXEIRA (INEP). Sinopse da Educação Superior 2014. Brasília: Inep, 2015. Disponível em: http://portal.inep.gov.br/web/guest/sinopses-estatisticas-da-educacao-superior. Acesso em: 13 mar. 2017.

LEHER, Roberto. Movimentos sociais, padrão de acumulação e crise da universidade. Trabalho para o GT 11. In: ASSOCIAÇÃO NACIONAL DE PÓS-GRADUAÇÃO EM EDUCAÇÃO - ANPED. 37., REUNIÃO NACIONAL ANPED, 2015, Florianópolis. Florianópolis, SC: UFSC, 2015. Disponível em:

http://www.anped.org.br/biblioteca/item/movimentos-sociais-padrao-de-acumulacao-e-criseda-universidade. Acesso em: 8 jul. 2017

MANCEBO, Deise; SILVA JUNIOR, João dos Reis; SCHUGURENSKY, Daniel. A Educação Superior no Brasil Diante da Mundialização do Capital. Educação em Revista, Belo Horizonte, v. 32, n. 4, p. 205-225, out./dez. 2016. Disponível em:

http://www.scielo.br/pdf/edur/v32n4/1982-6621-edur-32-04-00205.pdf. Acesso em: 11 jul. 2017.

MARTINS, José de Souza. A política do Brasil: Lúmpen e místico. São Paulo: Contexto, 2011.

MEDEIROS, Étore; FONSECA, Bruno. As bancadas da Câmara. In: Agência Pública. São Paulo, 2016. Disponível em: http://apublica.org/2016/02/truco-as-bancadas-da-camara/. Acesso em: 20 jul. 2017.

MEDEIROS, Marcelo; SOUZA, Pedro H. G. Ferreira de; CASTRO, Fábio Ávila de. O topo da distribuição de renda no Brasil: primeiras estimativas com dados tributários e comparação com pesquisas domiciliares (2006-2012). Dados-Revista de Ciências Sociais, Rio de Janeiro, v. 58, n. 1, p. 7-36, 2015. Disponível em:

http://www.scielo.br/pdf/dados/v58n1/0011-5258-dados-58-1-0007.pdf. Acesso em: 16 nov. 2016.

MÉSZÁROS, István. Para além do capital: rumo a uma teoria da transição. São Paulo: Boitempo, 2002.

MÉSZÁROS, István. O desafio e o fardo do tempo histórico: o socialismo no século XXI. São Paulo: Boitempo, 2007.

MINTO, Lalo Watanabe. As reformas do ensino superior no Brasil: o público e o privado em questão. Campinas, SP: Autores Associados, 2006.

MONFREDINI, Ivanise. As possibilidades de formação de sujeitos na Universidade In: A Universidade como espaço de formação de sujeitos. Santos: Leopoldianum, 2016. formato e-book, p. 7-20. Disponível em: http://unisantos.br/portal/editora/e-books/. 
OLIVEIRA, Francisco. O ornitorrinco. Disponível em:

http://antivalor2.vilabol.uol.com.br/textos/schwarz/schwarz_55.html. Acesso em: 20 mar. 2005.

PANIAGO, Maria Cristina Soares. Capital, controle social e participação autônoma dos trabalhadores no capitalismo em crise. R. Katál., Florianópolis, v. 15, n. 1, p. 122-130, jan./jun. 2012. Disponível em: http://www.scielo.br/pdf/rk/v15n1/a12v15n1.pdf. Acesso em: 20 jul. 2017.

PETHERICK, Anna. Austerity bites deeply. Institutions in Argentina and Brazil are struggling to maintain their funding and tale. Nature. Carees, USA, v. 548, p. 249-251, ago. 2017. Disponível em: http://www.nature.com/nature/journal/v548/n7666/full/nj7666249a.html?foxtrotcallback=true. Acesso em: 10 ago. 2017.

Instituto Brasileiro de Geografia e Estatística (IBGE). Pesquisa Nacional por Amostragem de Domicílio Contínua (PNAD Contínua). Disponível em:

http://agenciadenoticias.ibge.gov.br/agencia-sala-de-imprensa/2013-agencia-denoticias/releases/14903-no-trimestre-encerrado-em-junho-desocupacao-foi-de-13-0.html Acesso em 28 de ago. 2017.

RIBEIRO, Renato Janine. Coordenação para Aperfeiçoamento de Pessoal de Educação Superior Inserção social. Disponível em:

https://www.capes.gov.br/images/stories/download/artigos/Artigo_23_08_07.pdf. Acesso em: 14 ago. 2017.

SANTOS, José Antônio dos; DEUS, Sandra de. Um novo tempo da extensão universitária brasileira. Interfaces. Revista de Extensão, Belo Horizonte, v. 2, n. 2, p. 6-16, jan./jun. 2014. Disponível em: https://www.ufmg.br/proex/revistainterfaces/index.php/IREXT/article/.../113/pdf. Acesso em: 08 jan. 2016.

SINGER, Paul. Introdução à economia solidária. São Paulo: Fundação Perseu Abramo, 2003.

SOARES, Thiago J. C. C. et al. O sistema de inovação brasileiro: uma análise crítica e reflexões. Interciencia, Caracas, v. 41, n. 10, 2016. Disponível em:

http://www.uacm.kirj.redalyc.redalyc.org/articulo.oa?id=33947690011. Acesso em: 16 ago. 2017.

THOMAS, Hernán Eduardo. Tecnologias para inclusão social e políticas públicas na América Latina. In: OTTERLOO, Aldalice et al. Tecnologias sociais: caminhos para a sustentabilidade. Rede Tecnologia Social - RTS. Brasília/DF, 2009. p. 25-81. Disponível em: https://pt.scribd.com/document/54948001/Tecnologias-Sociais-Caminhos-para-asustentabilidade. Acesso em: 17 nov. 2016.

ZINGANO. Marco. Sobre o qualis periódicos 2015- Filosofia e o risco de sepukku. Revista ADUSP, São Paulo, n. 60, maio 2017. Disponível em: http://www.adusp.org.br/index.php/imprensa/revista-adusp/2872-maio-2017. Acesso em: 8 jun. 2017. 